\title{
Running or crossing? Children's expression of voluntary motion in English, German, and French
}

\author{
Henriëtte HENDRIKS ${ }^{1}$, Maya HICKMANN ${ }^{2 \dagger}$, and Carla PASTORINO-CAMPOS ${ }^{1}$ \\ ${ }^{1}$ University of Cambridge, UK and ${ }^{2}$ CNRS \& University Paris 8, France \\ Corresponding author: E-mail: hpjmh2@cam.ac.uk
}

(Received 20 February 2019; revised 11 December 2020; accepted 6 March 2021; first published online 22 April 2021)

\begin{abstract}
Much research has focused on the expression of voluntary motion (Slobin, 2004; Talmy, 2000). The present study contributes to this body of research by comparing how children (three to ten years) and adults narrated short, animated cartoons in English and German (SATELLITE-FRAMED languages) vs. French (VERB-FRAMED). The cartoons showed agents displacing themselves in variable Manners along different Paths (Path saliency and variance were specifically manipulated in four item types). Results show an increase with age across languages in how much information participants expressed. However, at all ages, more motion information was encoded in English and German than in French. Furthermore, language-specific features impacted the content and its organization within utterances in discourse, showing more variation within and across Path types in French than in the satellite-framed languages, resulting in later achievement of adult-like descriptions in this language. The discussion highlights the joint impact of cognitive and typological features on language development.
\end{abstract}

Keywords: voluntary motion expression; typology of spatial language; child language development

\section{Introduction}

Imagine a scene where a girl crosses a street on rollerskates. Lexicalizing this information (Talmy, 1985) presents a classical linearization problem (Levelt, 1981): the event encompasses two simultaneous sub-events (crossing and rollerskating), and one is not obviously more important than the other. It is up to the speaker to decide whether and how to prioritize the sub-events, e.g., by mentioning only one or by ordering them. And although most languages allow speakers to linearize the information as they see fit, such orders are likely to have discourse implications, given that each language type has a preferred way of lexicalizing information. The present study explores this issue further by comparing how children (three to ten years) and adults express voluntary motion across three languages: English, German, and French. The aim is to determine the extent to which the development of motion expression is influenced by language-specific features and Path types (across, up, down) in addition to general cognitive factors.

\footnotetext{
${ }^{\dagger}$ Author passed away during the writing of this article.

(C) The Author(s), 2021. Published by Cambridge University Press. This is an Open Access article, distributed under the terms of the Creative Commons Attribution licence (http://creativecommons.org/licenses/by/4.0), which permits unrestricted re- use, distribution and reproduction, provided the original article is properly cited.
} 
We first summarize language-specific means available for motion expression in the three languages, and indicate how this determines adult speakers' preferred expression and children's acquisition. We then present results from our cross-linguistic study examining participants' elicited productions. The discussion highlights the role of three main factors explaining the results: general cognitive factors, accounting for common developmental progressions across languages; language-specific factors, accounting for differences across and within language types; and the influence of Path types that may or may not result in further variation of motion expression, thereby potentially complicating the acquisition task for the child.

\section{Motion across languages: typological features}

According to Talmy (2000), voluntary motion involves an entity (i.e., the Figure, e.g., girl) moving with respect to another entity (i.e., the Ground, e.g., street), along a Path (i.e., across) and (optionally) a co-event, the Manner in which motion is carried out (e.g., rollerskating). A further possible co-event, Cause (the boy kicked the ball), was also identified by Talmy but is irrelevant for this study.

Talmy $(1985,2000,2012)$ identified several language types, including SATELLITE and VERB-FRAMED languages (hereafter S- AND V-LANGUAGES), which provide different lexicalization patterns for motion expression. S-languages (e.g., Germanic languages) typically express Manner in the main verb and Path in satellites such as particles (examples 1-2). In contrast, V-languages (e.g., Romance languages) lexicalize Path in the main verb and downplay Manner, either expressing it in the periphery or ignoring it altogether (example (3)).

(1) The wallaby skipped $[\mathrm{M}]$ across $[\mathrm{P}]$ Sidney Harbor Bridge.

(2) Eine Ameise krabbelte $[\mathrm{M}]$ aus $[\mathrm{P}]$ dem Ameisenhügel.

'An ant crawled out of the ant heap.'

(3) Gertrud Ederle a traversé $[\mathrm{P}]$ la Manche (à la nage $[\mathrm{M}]$ ).

'Gertrud Ederle crossed the English Channel (swimming).'

This typological difference applies particularly to events that denote a 'boundary-crossing' (Aske, 1989; Özçalişkan, 2015; Slobin \& Hoiting, 1994), i.e., a motion event involving a change of state (cf. examples (4) to (6)). It does not hold for motion events that lack a change of state, either because they take place within a general location (he is walking in the room) or because the intended goal of an event is not reached (he runs towards the school) (cf. Aske, 1989). In these cases, S- and V-languages (e.g., English (7) and French (8)) can both use Manner verbs.

(4) The old man strolled [M] across [P] the road.

(5) Das Mädchen ist über [P] die Strasse gehüpft [M].

'The girl skipped across the street.'

(6) Le chat a traversé [P] la route en marchant lentement [M].

'The cat crossed the road by walking slowly.'

(7) A seal was swimming [M] in the estuary [Loc].

(8) Le pingouin glisse [M] sur la neige [Loc].

'The penguin is sliding on the snow.'

Although these structures correspond to typical lexicalization patterns, they are not obligatory. In all languages, it is possible to use other means of expression depending on 
factors such as the relative importance of Manner information in the discourse situation. For example, English (9) shows the lexicalization pattern that is most typical of S-languages, while (10) deviates from this pattern, lexicalizing Path in the verb and expressing Manner in the periphery. Similarly, French (11) shows the pattern most typical of V-languages, while (12) shows a different one (Manner verb with prepositional phrase expressing Path). However, the fact that the expression of boundary crossings ideally is differentiated from other motion events in French may well lead to more varied expressions overall in this language than in English and German.

(9) The cat ran $[\mathrm{M}]$ away $[\mathrm{P}]$.

(10) The cat left $[\mathrm{P}]$ with a leap $[\mathrm{M}]$.

(11) Le chat est parti $[\mathrm{P}]$ (en courant $[\mathrm{M}]$ ).

'The cat left (running).'

(12) Le chat a couru $[\mathrm{M}]$ jusqu'en haut de l'arbre $[\mathrm{P}]$.

'The cat ran all the way to the top of the tree.'

\section{Influence of typology on adults' preferred expression}

Slobin $(1996,2003)$ argues that when speakers want to lexicalize scenes such as those described in examples (1) to (12) above, they need to be aware of the linguistic devices that are available in their language. They can then prepare their conceptualization of the event to make it fit with said devices. Slobin (1996) calls this requirement to fit the conceptualization with the language spoken 'thinking for speaking'.

The last decades have witnessed multiple studies assessing the extent to which motion expression is indeed influenced by specific properties of the speakers' language (cf. Allen, Özyürek, Kita, Brown, Furman \& Ishizuka, 2007; Berman \& Slobin, 1994; Filipović, 2007; Hickmann, 2003; Hickmann, Taranne \& Bonnet, 2009b; and Özçalişkan \& Slobin, 1999, 2003). Most of these studies compared the lexicalization of motion in verb- versus satellite-framed languages, to measure interand intra-typological differences. All of them have found robust differences in lexicalization patterns across S- and V-languages: as expected, Path is mostly expressed by the verb in V-languages and by satellites in S-languages (Berman \& Slobin, 1994; Filipović, 2007; Hickmann et al., 2009b; Özçalişkan \& Slobin, 1999, 2003); Manner is more frequently expressed in S-languages in more compact structures than in V-languages (Allen et al., 2007); and more information overall is expressed in S- than in V-languages (Hickmann et al., 2009b).

However, further in-depth research has also brought to light differences within typological groups: Harr (2012) indicates that the lexicalization of motion information in German is more typical of S-languages than in English: German speakers are more systematic in how they distribute information $(\mathrm{M}$ in the verb, $\mathrm{P}$ in other devices), and their utterances encode more information than those of their English counterparts.

Given these systematic differences within and across typological groups, one wonders when and how children learn these specific features of motion expression in their language. The next question asked therefore is: how early does children's motion expression within and across clauses become adult-like and language-specific? The following section discusses some of the existing studies addressing this question. 


\section{Motion expression across child languages}

Many studies have focused on the development of motion expression in children (Allen et al., 2007; Bowerman, 1996; Bowerman \& Choi, 2001; Choi, 2011; Bunger, Trueswell \& Papafragou, 2012; Choi \& Bowerman, 1991; Harr, 2012; Hickmann \& Hendriks, 2010; Hickmann, Hendriks \& Champaud, 2009a; Hickmann et al., 2009b; Ji, Hendriks \& Hickmann, 2011; Maguire, Hirsch-Pasek, Golinkoff, Imai, Haryu, Vanegas, Okada, Pulverman \& Sanchez-Davis, 2010; Naigles, Eisenberg, Kako, Highter \& McGraw, 1998; Özçalişkan \& Slobin, 1999; Papafragou, Massey \& Gleitman, 2002; Slobin, 1996, 2004). They have shown two main results. First, children observe cross-linguistic differences that follow from typological language properties. From very early on (around age three), children's motion descriptions differ across languages and resemble those of adults in their language more than those of same-aged children in other languages. Thus, from early on children's motion descriptions rely on the different structures available in the languages acquired. Children learning S-languages express both Manner (in the verb) and Path (in satellites) in compact one-clause structures (e.g., English run across). In contrast, children learning V-languages may use Path verbs (e.g., French monter 'to ascend', traverser 'to cross') whilst expressing Manner less frequently if at all (e.g., traverser [en courant] 'to cross [by running]'), or use Manner verbs whilst giving less information about Path in the same clause.

Second, in all languages examined, children express more motion components with increasing age. Thus, young children are more likely to encode either Manner or Path, but not both (cf. Bunger et al., 2012). Notwithstanding a general increase of Manner+Path responses with age, such utterances remain significantly more frequent in S- than in V-languages. It has been proposed that this may be because in the latter type languages speakers may need to rely on subordinate structures as a way to add Manner to the periphery of Path verbs (e.g., monter/descendre en courant 'to ascend/descend by running') (cf. Allen et al., 2007; Hickmann et al., 2009b; Özçalişkan, 2015). In other words, the combination of Path and Manner in $\mathrm{V}$-languages cannot always be expressed in one clause, which might cause an additional hurdle for young children. Existing studies have examined children at different ages, but all agree that acquisition is likely to evolve well into primary school years.

Few of the above studies, to our knowledge, have looked at the possible influence of the described Path types on variation within and across languages ${ }^{1}$. Hickmann, Hendriks, Harr and Bonnet (2018), however, showed that Path types can have such an influence: they found that combining multiple types of semantic information might be more challenging when referring to boundary-crossing events (across, into) than when referring to events expressing vertical motion (up, down) and relate this result to the fact that boundary-crossing involves a CATEGORICAL change of location, more difficult to express than vertical motion which involves a GRADUAL change of location.

The present study aims to shed further light on these issues, examining lexicalization patterns in the expression of voluntary motion, using the same elicitation procedure in seven age groups (three to ten years and adults) from three languages (English, German, French). Special attention is given to the diversity of motion expressions across different item types, with the items chosen to differ in Path saliency, and the availability or lack

\footnotetext{
${ }^{1}$ Allen et al. (2007) controlled for Manner type (inherent or not) but did not oppose different Path types.
} 
of a categorical boundary. To our knowledge, this is the largest and most complete study based on elicitation materials specifically designed for the expression of voluntary motion.

\section{Aims and hypotheses}

The aim of the present study is to determine the extent to which the development of motion expression is influenced by general cognitive factors on the one hand and language-specific factors and the specific information to be expressed on the other. If general cognitive factors were more influential, one would expect younger children to look more similar to each other than older children, who should look more like the adult speakers of their languages. If, however, language specific influences are stronger, children should at any point look more like the adult speakers of their language. Finally, if specific items are shown to influence expression, then this could create variability within as well as across languages.

A first set of analyses concerns (INFORMATION) LOCUS, which refers to the part of the sentence where Path and other types of information are encoded (main verb vs. other devices). Note that, in contrast to Talmy's strict definition of satellites, our coding included all devices other than the main verb. This allowed us to take into account the full diversity of additional expressions of both Manner (with a bike, en marchant 'walking', la patineuse 'the skater', or sur les pattes arrières 'on hindlegs'), and Path (von einer Seite zum anderen 'from one side to the other'). The second analysis examines response DENSITY (the number of different semantic components expressing the motion event).

We tested a number of hypotheses, partly based on previous findings as discussed above. The hypotheses have guided the statistical analyses we present below. Following on from the statistical analyses, we then attempted to explain how or why we find the attested phenomena by adding more detailed qualitative analyses.

First, given the fact that Path is the framing event for all motion events (there cannot be motion without Path), we expected Path expressions to be frequent and little impacted by item type or language-specific factors. Second, we expected that French speakers (V-language) should express Path in the verb, while speakers of English and German (S-languages) should express Path in other devices. Third, we expected children to show language-specific differences from early on, whilst also continuing to become more like the native speakers with age. We used qualitative analyses to look at the specific ages at which this change towards entirely adult-like expression occurs, and if ages are similar across languages. Fourth, more motion components should be expressed with increasing age in all languages. Note however that, for the latter hypothesis, an interaction between age and language is predicted, such that participants should produce more components in English and German than in French, particularly among young children. Finally, item type was expected to interact with the above factors (language, age) such that it should impact the type and number of expressed components both in adult speakers as well as in child data. In particular, and given the information provided in the items, we are expecting CONTROL items to be least dense as only Manner is salient in these items. We are furthermore expecting UP/DOWN items to be most dense (cf. Hickmann et al., 2018), but again, the effect might differ depending on languages and age. Note finally that we hypothesize that an attested variety across item types in the adult data may introduce a level of noise making the acquisition task for the child more complex. 


\section{Methodology}

\section{Participants}

A total of 468 monolingual participants took part in the study (156 per language). They belonged to seven age groups of approximately three, four, five, six, eight, ten years, and adults (cf. Table 1). Each age group comprised 24 participants except for the groups of three-year-olds (12 children per group). ${ }^{2}$ Children were tested in schools in the UK, France and Germany. Adults were university students in those countries.

\section{Stimuli}

Stimuli were animated cartoons (8-10 seconds) showing a Figure, animal or human, voluntarily performing a displacement. They represented four types of events: six showed vertical motion (first UP, then DOWN), six boundary crossing (ACROsS), and twelve only Manner against a grey background (CONTROL).

Test items (UP, DOWN, ACROSS) included three parts: a beginning (scene setting), a middle part including the targeted information (TARGET motion event), and an ending (Figure leaving scene). The target motion events were carefully controlled for and provided a clear Path (as in the item names) combined with typical Manners (crawling, climbing for animals, walking, cycling for humans). To make the cartoons more varied and interesting, the beginning and end parts were less controlled for. Analyses therefore focus on target motion events only. Appendix 1 summarizes all items and highlights (in bold) the targeted events. Appendix 2 illustrates one UP and DOWN item, an ACROSS item and a CONTROL item.

Contrary to many previous studies, this study included a set of 12 CONTROL items. Control items showed the same Figures as those in test items, but all background entities were removed, thereby maximizing Manner and minimizing Path saliency (cf. Appendix 2 mouse tiptoeing). The only potential Path information in these items consisted of forward motion against a blank screen. These items allowed to ensure that children knew the relevant Manner expressions in case they had not mentioned them in their descriptions of target events. They further provided interesting comparative material, as participants were free to construe a Path or to simply focus on the Manner of motion. ${ }^{3}$

\section{Procedure}

Participants were tested individually. All participants saw all stimuli and were assigned one of six random orders of item presentation (but equally distributed across genders). Test items were always shown before control items. ${ }^{4}$ After each item, participants were asked to narrate what had happened for someone who had not seen the cartoons.

\footnotetext{
${ }^{2}$ The smaller sample at three years was due to difficulties in finding enough children in England and Germany where few children go to school at three. It was decided to test smaller samples of 3-year-olds but in similar experimental situations, rather than to increase numbers but in different situations (e.g., home).

${ }^{3}$ We would like to thank one of our reviewers for pointing out that the fact that no information attracts attention to Path in these items may well allow them to elicit the most natural encoding of motion events.

${ }^{4}$ Previous results (Hickmann et al., 2009b) showed that the order in which test and control items were presented affected some results, e.g., when control items were shown first, participants focused more on Manner in French and more on Manner+Path in English.
} 


\begin{tabular}{|c|c|c|c|c|c|c|c|c|}
\hline & & age 3 & age 4 & age 5 & age 6 & age 8 & age 10 & Adults \\
\hline \multirow[t]{4}{*}{ English } & mean & $3 ; 3$ & $3 ; 11$ & $5 ; 0$ & $6 ; 1$ & $8 ; 1$ & $10 ; 0$ & n.a. \\
\hline & range & 2;11-3;6 & $3 ; 6-4 ; 5$ & $4 ; 6-5 ; 5$ & $5 ; 10-6 ; 5$ & $7 ; 6-8 ; 9$ & $9 ; 6-10 ; 6$ & n.a. \\
\hline & gender & $7 f / 5 m$ & $12 \mathrm{f} / 12 \mathrm{~m}$ & $12 \mathrm{f} / 12 \mathrm{~m}$ & $12 \mathrm{f} / 12 \mathrm{~m}$ & $12 \mathrm{f} / 12 \mathrm{~m}$ & $12 f / 12 m$ & $12 \mathrm{f} / 12 \mathrm{~m}$ \\
\hline & $\mathrm{N}$ & 12 & 24 & 24 & 24 & 24 & 24 & 24 \\
\hline \multirow[t]{4}{*}{ German } & mean & $3 ; 5$ & $4 ; 5$ & $5 ; 5$ & $6 ; 1$ & $8 ; 6$ & $10 ; 7$ & n.a. \\
\hline & range & $3 ; 0-3 ; 8$ & 3;8-4;11 & $5 ; 0-6 ; 2$ & $5 ; 8-6 ; 6$ & 7;10-9;3 & $10 ; 0-11 ; 4$ & n.a. \\
\hline & gender & $6 f / 6 m$ & $13 \mathrm{f} / 11 \mathrm{~m}$ & $12 f / 12 m$ & $12 \mathrm{f} / 12 \mathrm{~m}$ & $12 \mathrm{f} / 12 \mathrm{~m}$ & $12 \mathrm{f} / 12 \mathrm{~m}$ & $13 \mathrm{f} / 11 \mathrm{~m}$ \\
\hline & N & 12 & 24 & 24 & 24 & 24 & 24 & 24 \\
\hline \multirow[t]{4}{*}{ French } & mean & $3 ; 2$ & $4 ; 5$ & $5 ; 3$ & $6 ; 4$ & $8 ; 6$ & $10 ; 3$ & n.a. \\
\hline & range & $2 ; 11-3 ; 10$ & $3 ; 10-4 ; 10$ & $4 ; 11-5 ; 10$ & $5 ; 9-6 ; 9$ & $7 ; 9-8 ; 9$ & $9 ; 2-11 ; 8$ & n.a. \\
\hline & gender & $7 f / 5 m$ & $12 \mathrm{f} / 12 \mathrm{~m}$ & $12 f / 12 m$ & $12 f / 12 m$ & $11 \mathrm{f} / 13 \mathrm{~m}$ & $14 \mathrm{f} / 10 \mathrm{~m}$ & $12 f / 12 m$ \\
\hline & $\mathrm{N}$ & 12 & 24 & 24 & 24 & 24 & 24 & 24 \\
\hline
\end{tabular}


Young children (three to five) were presented with a blindfolded doll and asked to tell her what happened. Older children and adults were instructed to address a fictitious naïve interlocutor.

All sessions started with a training item (a frog jumping into a pond). During this item, the experimenter helped participants focus on different motion components ("Okay, so what did the frog do?"). Hereafter, the experimenter did not intervene. The entire session was audio-recorded, transcribed and coded.

\section{Coding}

All data were coded at the clausal level. A clause was defined as the expression of a proposition minimally containing a verb, including inflected forms, infinitives and gerundives.

The analyses focus on the part of the response that described the target event (hereafter 'target responses'). Responses could involve a sentence containing a single clause (90\% of all responses analyzed) as in (13), or several clauses with subordination (14), coordination (15) or juxtaposition (16). In cases of single clause and subordinated responses (13 and 14) the whole response was automatically selected as target response. However, when responses contained coordinated or juxtaposed clauses ( $8 \%$ of all clauses), only one was selected as the 'main target response' and others were coded as 'potential target responses'. Selection in these cases was based on two criteria. Semantic richness was the main criterion: if one clause contained more motion components than the other, it was considered the target response. Thus, skating was identified as the target response in (16) because it expresses Manner, whereas going on snow expresses neither Path nor Manner. When clauses were equally rich (15), priority was given to Path expression, as the most crucial defining feature of motion (cf. Talmy, 2000). As a result, the clause et qui traverse une rue 'and who crosses a street' was identified as the target.

(13) $[\mathrm{He}]$ slid $[\mathrm{M}]$ across $[\mathrm{P}]$ the frozen river. (Eng-10yrs)

(14) [Une femme blonde] pédale à vélo $[\mathrm{M}]$ pour traverser $[\mathrm{P}]$ une voie ferrée. (Fren-Adult)

'A blond woman is peddling a bike to cross a railroad track.'

(15) Alors c'est un bébé qui marche à quatre pattes $[\mathrm{M}]$ et qui traverse $[\mathrm{P}]$ une rue. (Fren-10yrs)

'So, it's a baby that walks on all fours and that crosses a street.'

(16) He's skating $[\mathrm{M}]$. He's going on some snow [Loc]. (Eng-03yrs)

Each resulting target response was coded for number and type of motion components, and how they were encoded within the clause. For this purpose, two loci were identified: 'verb' (main verb) and 'other devices' (any other linguistic items). For density coding, only semantic information from distinct categories was considered (several expressions of Path counted as density $=1$, but one expression of Manner and one of Path counted as density $=2$ ). In voluntary motion expressions, the maximum possible density therefore is $2 .^{5}$

\footnotetext{
${ }^{5}$ One reviewer pointed out that the term density seems somewhat cumbersome, as the maximum information to be expressed in voluntary motion is Path+Manner. Although this is indeed the case for voluntary motion, caused motion events potentially express more semantic information (cf. Hickmann et al., 2018). As we ran a study on voluntary and caused motion within the same population, we decided to use the same terminology and measures for ease of comparison across studies.
} 


\section{Analyses}

For our quantitative analyses, two linear mixed-effects models were fitted, utilizing mean Path expression (analysis 1), and mean response density (analysis 2) as the dependent variables. All analyses included language (English, German and French), age (three, four, five, six, eight, ten and adults), item type (ACROSS, UP, DOWN, CONTROL) and gender (Male vs. Female) as fixed effects, as well as interactions between language, age and item type. Results showed no effects of gender nor any interaction between this factor and other factors, so gender is ignored in subsequent analyses.

Locus (verb vs. other) and interactions between locus and all other fixed effects (excluding gender) were additionally introduced as fixed effects in analysis 1 , to be able to address the questions of interest. A random-effects structure was specified to account for the hierarchical nature of the data and to control for non-systematic variation. For all models fitted, random intercepts for participants, language and age were included. Planned contrasts were specified in those instances when more than two factors were compared (cf. Appendix 3). The analyses were conducted in $\mathrm{R}$ version 3.4.3 (R Core Team, 2017) using the nmle package (Pinheiro, Bates, Debroy, Sarkar \& R Core Team, 2018).

For our qualitative analyses, the actual participant responses were surveyed by an expert to identify both the trends in the behaviour of the participants with regards to the research questions, and specific examples of the phenomena identified.

\section{Results}

\section{Expression of Path and Information Locus}

Our first analysis first of all indicated an effect of Language showing that French overall Path expression was significantly lower than in English and German $(b=0.21, t(445)=$ 68.72, $p<.001)$, whereas no difference was found between German and English. An overall age effect was also observed showing significant differences in all age contrasts and indicating a steady overall increase of Path expression with age across all three languages (cf. Table 2). Finally, an overall effect of item type occurred: in all languages and age groups, CONTROL items showed significantly fewer Path expressions than test items $(b=-0.09, t(3106)=-36.54, p<.001)$; ACROSS items showed fewer Path expressions than vertical items $(b=-0.06, t(3106)=-16.75, p<.001)$, and significantly less frequent expressions for UP than for DOWN items $(b=-0.03$, $t(3106)=-5.16, p<.001)$. However, these results must be understood in the context of several interactions. Thus, both age and item type interacted with language. As can be seen in Figure 1, the interactions between age and language likely occurred because developmental paths were different across the three languages. Item type interacted with language because it impacted on Path expression more in French than in English and German.

This is supported by our qualitative analyses, which showed that our adult participants in particular differed considerably in terms of the variation of Path expression across item types. Thus, French adults clearly distinguished between item types, and expressed Path most frequently in vertical items, less so in ACROss items, and only minimally in CONTROL items. In other words, they more consistently expressed Path with gradual changes of location, less so with canonical changes of location, and were happy to present the CONTROL items as events happening in a 
Table 2. Age effect (contrasts) in Mean Path analysis

\begin{tabular}{lccccc}
\hline & Value & Std. Error & DF & t-value & p-value \\
\hline 3- vs 4-yrs & -0.15 & 0.01 & 445 & -10.58 & $<.001$ \\
\hline 4- vs 5-yrs & -0.22 & 0.02 & 445 & -14.25 & $<.001$ \\
\hline 5- vs 6-yrs & -0.25 & 0.02 & 445 & -16.34 & $<.001$ \\
\hline 6- vs 8-yrs & -0.24 & 0.01 & 445 & -15.86 & $<.001$ \\
\hline 8- vs 10-yrs & -0.22 & 0.01 & 445 & -16.25 & $<.001$ \\
\hline 10-yrs vs Adults & -0.18 & 0.01 & 445 & -17.47 & $<.001$ \\
\hline
\end{tabular}

Control

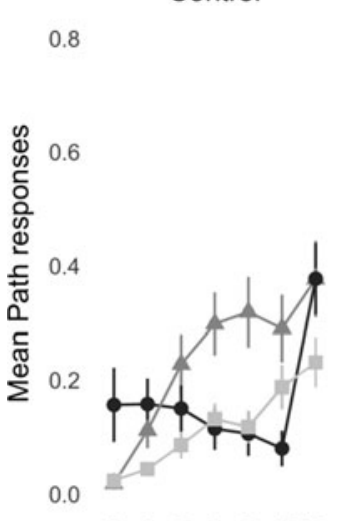

Across

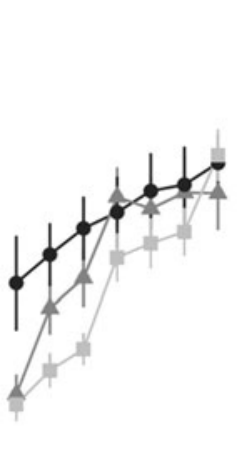

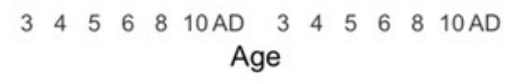

Up

Down

$\begin{array}{llllll}3 & 4 & 5 & 6 & 8 & 10 \mathrm{AD}\end{array}$

Language $-\phi$ - German - English - French

Figure 1. Interaction between Language, Age, and Item type affecting mean Path responses

general location. In contrast, English and German adults' mean Path expressions across the four item types were more similar, indicating that this factor impacted less on their Path expressions. French adults thus seem to be more sensitive to the motion information provided in the item types whereas English and German adults seem inclined to express very similar information across them. As a result, French children may find themselves with slightly more "noisy" or diverse input, which may well complicate their acquisition.

In fact, although children seemed to overall mirror the adult expressions, they all seemed to distinguish between the various item types more than the English and German adults. They furthermore all found it harder to produce adult-like expressions for the CONTROL and ACROSS items than for the vertical items. As regards CONTROL items, English and French children started off expressing virtually no Path information, hence construing the motion as happening in a general location. French children continued to add little Path information (cf. example 17), thereby following the trend of the French adults; but English children increasingly added (inferred) Paths (18). By age ten 
both groups of children ended up looking close to adult-like. German children, interestingly, started out by providing Paths to their CONTROL item descriptions, but then increasingly provided only Manner (19), thus looking least like the German adults at age ten.

(17) Là c'est une petite fille qui fait du patin. (Fren-08yrs)

'There it's a little girl who is ice-skating.'

(18) The boy skidded across the lake. (Eng-08yrs)

(19) Das Eichhörnchen hüpft oder springt. (Ger-10yrs)

'The little squirrel hops or jumps.'

For the ACROSS items the French and English children showed an increase in Path expression most clearly at earlier ages (cf. examples 20 and 21 for a French four-year-old and an adult, respectively), whereas German children seemed close to adult-like from age three. English children reached that stage around age six and French children did not quite reach it at age ten. Finally, Path expression in vertical items was adult-like at all ages in German, reached adult-like expression at three years for UP and 6 years for DOwN expressions in English and failed to reach adult-like expression in French. Thus, French children overall indeed seem to achieve adult-like expression later than the children acquiring S-languages.

(20) Y [: il y] a une fille sur le vélo [M] et puis elle a roulé [M] sur les rails [Loc] du train. (Fren-04yrs)

There's a girl on a bicycle and then she has rolled on the train tracks.

(21) alors y a une dame en vélo $[\mathrm{M}]$ qui suit la route $[\mathrm{P}]$ et qui traverse une voie ferrée $[\mathrm{P}]$. (Fren-Adult)

So there's a lady on a bike who follows the road and who crosses the railroad tracks.

Figure 2 illustrates our analysis with the added factor locus. The analysis showed a main effect of locus, indicating that average Path expression was significantly lower in verbs than in other devices $(b=0.31, t(3106)=-52.57, p<.001)$. Interactions also occurred. A two-way interaction between locus and language was observed: contrasting French with the S-languages $(b=-0.41, \mathrm{t}(3106)=-99.37, p<.001)$, French, as expected, mainly expresses Path in the verb, whereas English and German mainly express Path in other devices. The contrast between English and German was also significant $(b=-0.02 \mathrm{t}(3106)=-3.18, p .0015)$, indicating a more systematic expression of Path in other devices in German as compared to English. Finally, a three-way interaction between locus, age and language was significant for all age contrasts ( $p$-values were all under the .05 significance threshold), except for eight to ten-year olds. This interaction results from an increase of Path scores that is more prominent in other devices than in verbs, and although this is true for all three languages, it is less visible in German, more pronounced and more gradual in English, and only happens between 10 years and adult age in French.

Notwithstanding the above results showing clear V- versus S-framed tendencies, qualitative analyses at the same time indicated that French speakers used more varied constructions than S-language speakers. Thus, whereas English and German adults used very similar structures to express both Manner (in verb) and Path (in other devices) across the four item types (cf. English examples 22-25 from one single 

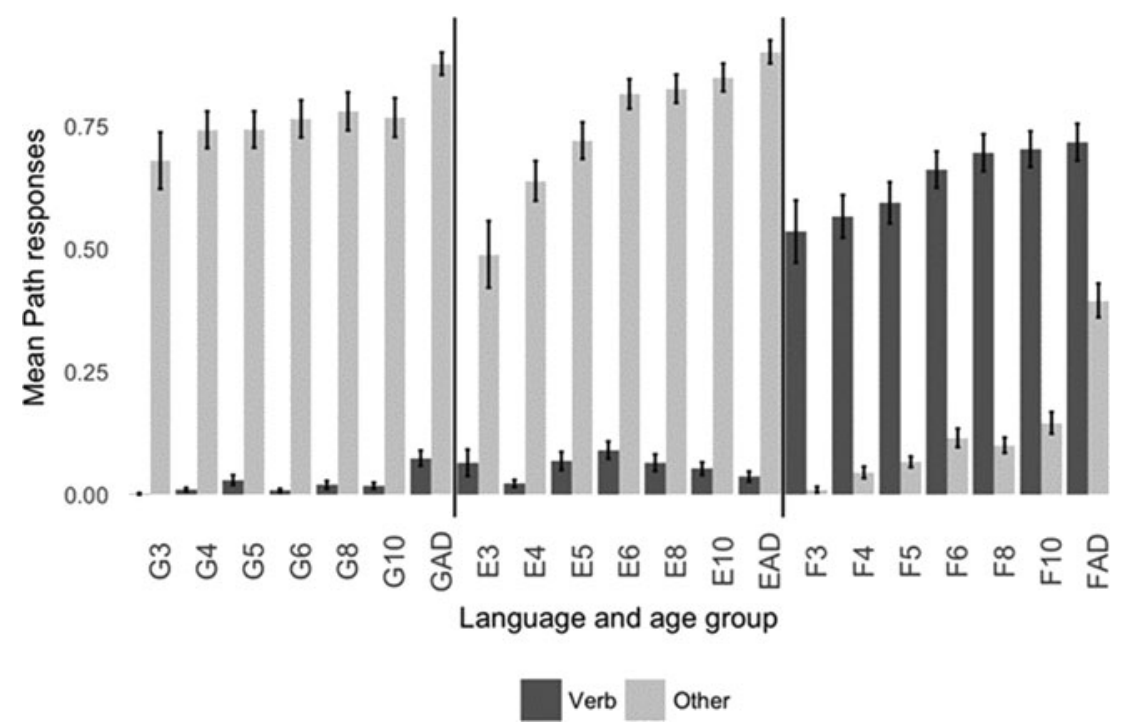

Figure 2. Mean Path responses in verb vs. other devices $(G=$ German, $E=$ English, $F=$ French $){ }^{6}$

adult, for CONTROL, ACROSS, UP and DOWN items respectively), French adults may use a diverse array of structures across and also within item types, as in French examples 26-29 from a single adult (26: CONTROL; 27-29: ACROSs). This diversity, which is most pronounced in the adult data for ACROSs items may result in some further noise in the input that may well have led French children to reach adult-like lexicalizations later than German and English children or not at all.

(22) A cat bounces $[\mathrm{M}]$ across $[\mathrm{P}]$ from left to right (Eng-Adult)

(23) There's also a baby crawling $[\mathrm{M}]$ across $[\mathrm{P}]$ (Eng-Adult)

(24) A squirrel $[\ldots]$ climbs $[\mathrm{M}]$ up $[\mathrm{P}]$ a tree (Eng-Adult)

(25) And then climbs $[\mathrm{M}]$ back down [P] (Eng-Adult)

(26) Là un ours qui marche $[\mathrm{M}]$ (Fren-Adult)

There a bear who walks

(27) un homme qui traverse $[\mathrm{P}]$ une route de gauche à droite $[\mathrm{P}]$ en courant $[\mathrm{M}]$ (Fren-Adult)

A man who crosses a road from left to right while running

(28) Une femme qui pédale à vélo $[\mathrm{M}]$ donc pour traverser $[\mathrm{P}]$ des rails (Fren-Adult)

A woman who peddles on a bike in order to cross the railroad tracks

(29) il glisse $[\mathrm{M}]$ jusqu'à l'autre rive $[\mathrm{P}]$ (Fren-Adult)

He slides all the way to the other bank

\section{Mean response density}

To assess the influence of language, age and item type on mean utterance density, we ran a second linear mixed-effects model. Results show an effect of language indicating that density in French was significantly lower than in the S-languages $(b=0.13, t(445)$

${ }^{6}$ Error bars represent the standard error of mean 
$=22.60, p<.001)$ and density in English was also significantly lower than in German $(b$ $=0.04, t(445)=3.65, p=<.001$ ). An effect of age was also observed (cf. Table 3), indicating a steady overall increase of density with age.

However, as shown in Figure 3, language and age also interacted significantly. Although density increases in all three languages, the developmental path before the age of eight looks distinctly different for English children (steeper developmental curve) compared to French and German children. From eight years onwards, the developmental path is similar across all ages.

As shown in Figure 4, an effect of item type was also observed, such that responses to CONTROL items, as expected, were significantly less dense than test items $(b=-0.06, t$ $(1329)=-16.62, p<.001)$; in addition, Down items elicited significantly less dense responses than UP items $(b=0.09, \mathrm{t}(1329)=10.49, \mathrm{p}<.001)$. Differences between ACROSS and vertical items were not significant. These results must be qualified because of a significant interaction between item type and language that is best described as follows: differences between French and the S-languages $(b=-0.02, t$ $(1329)=-8.80, p<.001)$ occurred because difference in density across the four items was large in French (DOWN and CONTROL items < ACROSS and UP items) whereas German and English participants seemed to mainly differentiate CONTROL items from all others $(b=-0.04, t(1329)=-8.75, p<.001)$.

A three-way interaction between item type, age and language is also significant, indicating that the developmental trends in density fluctuate to some extent with item types, as well as with age and language. Thus, English density seems least impacted by item type, showing a clear increase in all item types, German density seems to increase only with CONTROL items but is relatively high from three years with the test items, and finally density in French again seems to be most influenced by item type: an increase in density over age in this language is almost non-existent for DOWN items, slightly more prominent for CONTROL items and most prominent for UP and ACROSS items.

Qualitative analyses suggest that the youngest French children tend to produce short utterances with only the verb carrying motion information (no other devices). As a result, they need to make a "forced choice" between Path or Manner. It seems that they tend to choose Manner verbs for CONTROL items, Path verbs for vertical items (even if less frequently than the adults) and a mix of choices for the ACross items. Only when responses become more elaborate can they express both types of information (cf. also the factor locus above). As French adults provide input in which motion events are described in relatively varied ways (examples 26-29 above), children may correctly assume that choosing either Manner or Path is acceptable in their language, but not quite get the proportions correct.

Our in-depth analyses of the data can further explain why expressions in French are overall less dense for DOWN and CONTROL items than for ACROSS and UP items and why these differences are less pronounced in the S-languages. In French, Down items at all ages mostly attracted Path information only (i.e., (re)descendre 'go down (again)'), most probably because the Manner of motion had already been mentioned in the upwards movement (cf. example 30). English and German participants, in contrast, were more likely to repeat the Manner information as well or give more detailed Manner information as in (31). The density of French responses to UP items is unexpectedly high in the adult data because participants prefer the verb grimper (climb.up) (cf. 30) which allows for the lexicalization of both Manner and Path in French over the verb monter (go.up). Children slowly increase density levels towards the adult norm, whilst 
Table 3. Age effect (contrasts) in Density analysis

\begin{tabular}{lccccc}
\hline & Value & Std. Error & DF & t-value & p-value \\
\hline 3- vs 4-yrs & -0.27 & 0.03 & 445 & -10.32 & $<.001$ \\
\hline 4- vs 5-yrs & -0.40 & 0.03 & 445 & -13.93 & $<.001$ \\
\hline 5- vs 6-yrs & -0.47 & 0.03 & 445 & -16.38 & $<.001$ \\
\hline 6- vs 8-yrs & -0.47 & 0.03 & 445 & -16.65 & $<.001$ \\
\hline 8- vs 10-yrs & -0.39 & 0.03 & 445 & -15.58 & $<.001$ \\
\hline 10-yrs vs Adults & -0.27 & 0.02 & 445 & -14.27 & $<.001$ \\
\hline
\end{tabular}

German

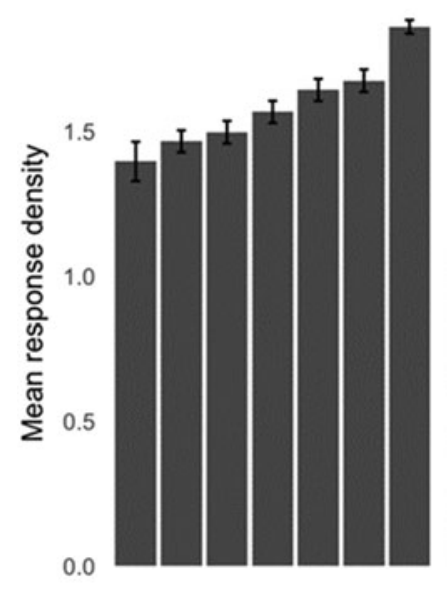

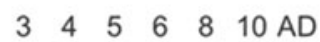

English

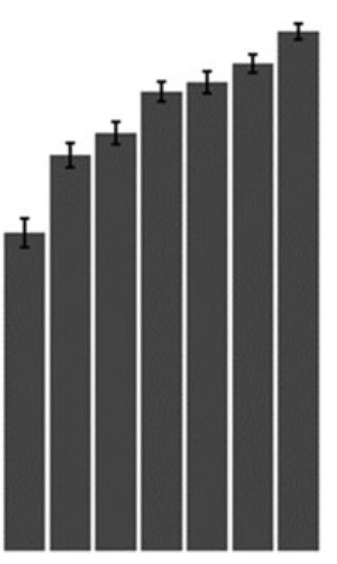

$\begin{array}{lllllll}3 & 4 & 5 & 6 & 8 & 10 & \mathrm{AD}\end{array}$ Age group
French

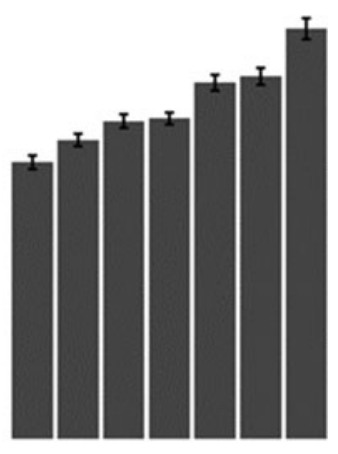

$\begin{array}{llllll}3 & 4 & 5 & 6 & 8 & 10\end{array}$

Figure 3. Mean response density (= mean number of semantic components (Path, Manner) expressed in each target response) as a function of language and age. ${ }^{7}$

also differentiating between the different item types but become closer to adult levels of density earlier with CONTROL and DOWN items in which only a verb is needed to express the typical information provided also in the adult data (Manner in CONTROL items, Path in DOWN items). In other words, where additional information beyond that encoded in the verb is needed (i.e., ACrOss items) French children take longer to start looking entirely adult-like in their expression of motion.

(30) Un écureuil qui grimpe le long d'un arbre [...] et qui redescend. (Fren-Adult) 'A squirrel that climbs.up along a tree [...] and that descends back down.'

(31) [The mouse] is running $[\mathrm{M}]$ up $[\mathrm{P}]$ the table leg $[\ldots]$ sliding $[\mathrm{M}]$ down $[\mathrm{P}]$ the table. (Eng-Adult)

\footnotetext{
${ }^{7}$ Error bars represent the standard error of mean
} 


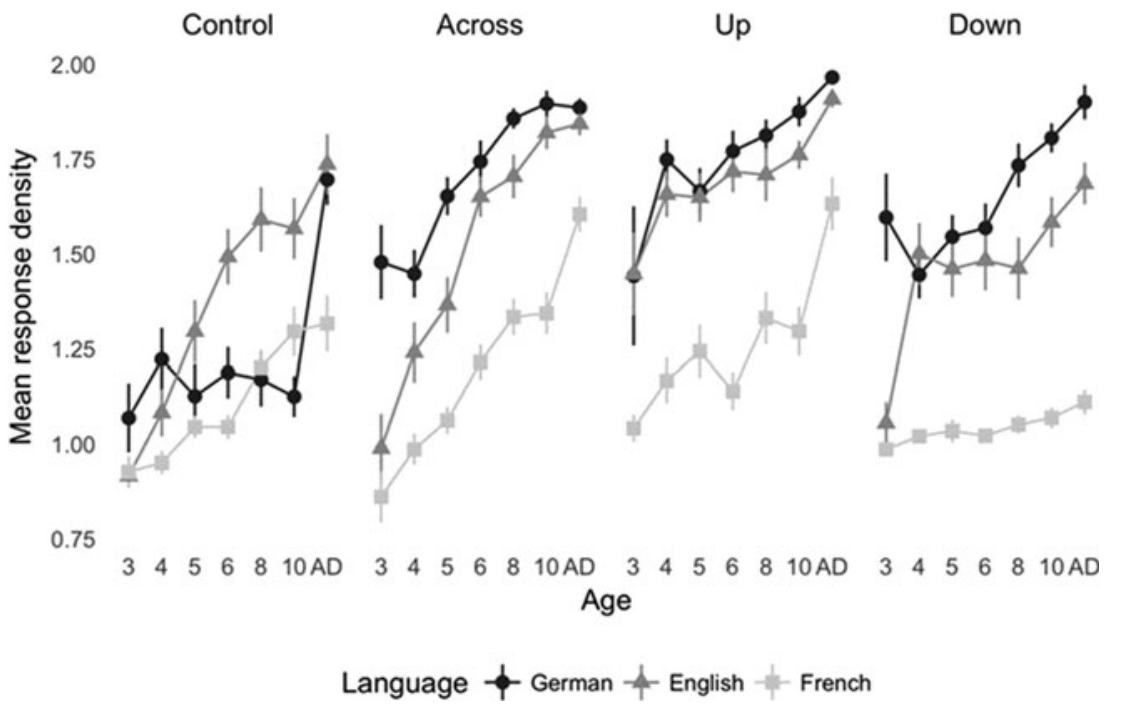

Figure 4. Interaction between age, language and item type affecting mean response density

Table 4. Age effect (contrasts) in Architecture analysis

\begin{tabular}{lccccc}
\hline & Value & Std. Error & DF & t-value & p-value \\
\hline 3- vs 4-yrs & 0.04 & 0.01 & 445 & 3.26 & .0012 \\
\hline 4- vs 5-yrs & 0.05 & 0.01 & 445 & 4.17 & $<.001$ \\
\hline 5- vs 6-yrs & 0.08 & 0.01 & 445 & 5.71 & $<.001$ \\
\hline 6- vs 8-yrs & 0.08 & 0.01 & 445 & 6.03 & $<.001$ \\
\hline 8- vs 10-yrs & 0.06 & 0.01 & 445 & 5.66 & $<.001$ \\
\hline 10-yrs vs Adults & 0.06 & 0.01 & 445 & 7.12 & $<.001$ \\
\hline
\end{tabular}

\section{Discussion}

This study compared voluntary motion expression in participants of different ages (three to ten years and adults) in three languages: English, German, and French. Our main aim was to determine the influence of language-specific constraints in addition to general cognitive factors on spatial language development. We furthermore wanted to understand how item types might influence expressions across languages and ages, given the different types of information represented in them, and in particular if they might create variation of expression within a language that might then complicate the acquisition task of the child. The discussion addresses three points: the common developmental patterns observed across all three languages, the language-specific patterns observed within and across language types, and the impact of item type. In addition, the discussion suggests the potential implications of the results for language and cognitive development. 


\section{Common developmental progressions across languages}

All three languages showed similar developmental progressions. As predicted, from three years on, response density increased gradually in all three languages, i.e., children expressed more motion information with increasing age (Manner plus Path rather than just Manner or Path). Presumably, these common developmental progressions result from increasing cognitive capacities underlying this task. We know that by the age of three (our starter age) children already have a good understanding of space, e.g., they notice changes in Path or Manner as early as 9 months (Pulverman, Song, Pruden, Golinkoff \& Hirsch-Pasek, 2013) and can categorize events based on Path and Manner as early as 15 months (Pruden, Hirsch-Pasek \& Golinkoff, 2008) (cf. Allen et al., 2007 for a similar discussion). However, even if children are shown to attend to different parts of an event with similar timing as adults (as measured by eye-tracking) they are shown not to necessarily express the same information in a linguistic task (Bunger et al., 2012). They continue to develop their understanding and expression of motion until well into their late primary school years (Newcombe, Uttal \& Sauter, 2013). And even if children may understand basic spatial configurations early, that knowledge does not necessarily translate directly into linguistic expression given the variation that is observed within and across languages which may or may not match these configurations. Furthermore, this type of linguistic task requires that children hold in memory several aspects of motion information simultaneously, a capacity that continues to improve until a later age or even until adulthood (Cowan, 2014; Delage \& Frauenfelder, 2019; Gathercole, 1999; Nys, Gyselinck \& Hickmann, 2016). Finally, research (Hickmann, 2003) shows that it takes children some time (not before seven years) to learn to organize discourse, which is essential in this task to decide what motion information needs expressing based on the saliency of the presented information and on the shared knowledge (or lack thereof) between speaker and hearer. The more general developmental trajectory is therefore likely related to a variety of causes, including the development of working memory and the child's acquisition of the production of cohesive and coherent discourse.

\section{Language-specific patterns within and across language types}

Notwithstanding this common progression, responses differed across languages both within and across typological groups. First, as predicted, English and German (S-languages) clearly differed from French (V-language), in that they expressed Path almost solely in devices other than the verb. This was true at all ages and Path expression in this locus became even more frequent with age. French (V-language) on the contrary showed highly frequent Path expression in the verb from the earlier ages onwards. However, in this language the contrast between loci reduced with age, as increasingly more Path expressions occurred outside of the verb, resulting in some more elaborate marking (different aspects) of Path information in this language or the gradual marking of Path and Manner. Overall, though, these findings support our locus hypothesis (Path in verb in French, in satellite in English and German).

As also predicted, considerable differences were found in response density, which was highest in German, slightly lower in English (S-languages) and lowest in French (V-language) at all ages including among adults.

Our findings correspond to previous results relying on Talmy's typology, and previous studies in child language acquisition (Allen et al., 2007; Berman \& Slobin, 
1994; Özçalişkan \& Slobin, 1999, 2003): all these studies show the same division of labor between verbs and other devices in V- versus S-languages as our study. And they also provide evidence for the more frequent encoding of multiple types of information in S-languages as compared to V-languages (Allen et al., 2007 for English versus Turkish and Japanese; Özçalişkan \& Slobin, 1999 for English versus Spanish and Turkish; Hickmann et al., 2009b for English versus French).

The current study, however, also observed some unexpected differences within the S-languages, i.e., German children produced adult-like responses earlier than English children. Presumably, this result is due to the different linguistic means available in German as compared to English, particularly for the expression of Path, i.e., case markings, particles, and double Path markings in prepositions and particles, as in example (32). As a result, these multiple markers ${ }^{8}$ reinforce Path information and may speed up the acquisition of such markers by German children (cf. similar arguments in Harr, 2012 and Slobin, Bowerman, Brown, Eisenbeiss \& Narasimhan, 2011).

(32) Dann steigt $[\mathrm{P}+\mathrm{M}]$ er auf $[\mathrm{P}]$ die Palme rauf $[\mathrm{P}]$. (Ger-10yrs)

Lit. Then climbs.up he on the palm tree upwards.

'Then he climbs up on the palm tree.'

More importantly, previous studies lacked a careful control of different event (item) types, which were introduced in this study, thus allowing for further insights into language-specific differences. Remember that we introduced a CONTROL item that specifically downplayed Path salience and that a clear boundary-crossing event (ACROsS) was contrasted with vertical items, which imply a more gradual change of state (UP and DOWN). As predicted, responses varied with the type of item described. In all three languages, density was highest with the vertical item UP and lowest with the CONTROL items. Across items showed most progression in density across ages in all three languages. Down events showed lower density than UP events, presumably because they were systematically presented right after and in the same cartoon as the UP events, leading speakers to delete Manner information already available in the discourse context. As mentioned in the introduction, a previous study on caused motion (Hickmann et al., 2018) already proposed that gradual changes of location (vertical motion, e.g., UP) might be easier to express and perhaps to conceptualize than categorical changes of location (boundary crossing). This could explain why ACROSS items in all languages lag at early ages. The fact that CONTROL items receive little expression of Path can be explained because of the low Path salience.

However, although this trend was true for all three languages, careful and qualitative analyses of these items further indicated that French adult speakers distinguish more clearly between these item types in terms of Path expression, locus and density than S-language speakers. Control items, even by French adults are quite likely to be reported including Manner information only, whereas Down information is reported with almost exclusively Path information.

Our qualitative analyses furthermore showed that whereas English and German adults tend to use very similar lexicalization patterns across all four item types, French adults may vary their lexicalization across but also within item types. As a

\footnotetext{
${ }^{8}$ Recall that multiple markers of the same type (i.e., multiple Path markers) are only counted once in the density analysis.
} 
result, the French input will overall be more varied and subtly differentiated than the S-language input, potentially creating some additional acquisition challenges for French children compared to the S-language learning children. And indeed, although children at three years seem to look more like the native speaking adults of their language than like other three year old children, French children seem to take longer to express the motion information comparable to the French adults, often not looking adult-like even at the age of ten. The variation in the treatment of different items is particularly clear in our density results, where French three-year-olds already show a distinction between the different item types whereas English and German children seem to provide similar density levels across the various items (CONTROL items excluded). The lack of adult-like expression in French is best seen in the mean Path analysis, where a considerable gap between Path expression in ten-year-olds and adults still exist in this language (most clearly for the vertical items).

\section{Implications for language and cognitive development}

Although our data show a clear developmental progression in terms of density in all three languages, making it likely that language acquisition is partly guided by similar underlying cognitive processes, clear differences between S- and V-languages were also found. First, as previously mentioned, French native speakers (adults and children) show most variation in their choices of lexicalization when describing motion events and seem most sensitive to the event types they describe. As a result, even French adults do not systematically express Path in the verb. This is mainly influenced by the perceived saliency of Manner and Path in the item types described. Thus, in the CONTROL items, that downplayed Path saliency and hence foregrounded the Manner of the action, French speakers chose a Manner verb and ignored Path information. This finding seems to contrast with those reported by Allen et al. (2007) and Özçalişkan and Slobin (2003) for Turkish, which show a very clear preference for the expression of Path in the verb and Manner (when expressed) in other devices. We proposed that the alternative structures in French as exemplified in (26-29 above) increased the variety in the input, leading to the diverse patterns of Path expression observed in French at all ages.

We further proposed that this variety in the treatment of individual items may also impact the progression in density. Note that it is certainly not the case that French native speakers cannot produce dense motion responses. In fact, they do so frequently (especially among ten-year-olds and adults), as in the striking example produced by an adult in (33). Second, when looking beyond the domain of voluntary motion, research has shown that French at times encodes denser information than English: when expressing caused motion for example, French adult native speakers' expressions are as dense as those of English and German speakers. In such cases the French adults show a large variety of different expressions including many constructions including subordination, allowing them to express multiple types of information, resulting in a mean response density of three. Example (34) from Hickmann et al. (2018) shows an even denser response expressing five pieces of motion information.

(33) Alors une chenille [...] qui traverse l'écran de droite à gauche et heu, donc traverse en glissant mais en faisant avec son corps un geste d'accordéon, c'est à dire se plie en deux pour avancer. (Fren-Adult) 
'So, a caterpillar that crosses the screen from right to left and ehm, so crosses the screen by sliding but making the movement of an accordion with its body, in other words (it) folds itself in two in order to go forward.'

(34) Popi grimpe [Agent $\mathrm{M}+\mathrm{P}]$ sur la dune, en poussant [Cause+Manner of Causing motion] devant lui la bouée qui tourne [Object $\mathrm{M}$ ] dans le sens inverse des aiguilles d'une montre. (Fren-Adult)

'Hoppy climbs up on the sand dune, pushing in front of him the swimming ring that turns in counter-clockwise direction.'

In sum, although French speakers typically express Path in the verb and do not necessarily express Manner, the present findings have unveiled a much richer set of patterns in this language than in the other languages. Whereas Talmy's description for S-languages holds for most motion event types, the description for V-languages holds only for boundary crossing events, and variation occurs depending on the salience of both Manner and Path in this language. These varied patterns in the input to the child seem to lead to a later acquisition, thereby delaying adult-like lexicalization and dense expression of motion. However, they also reveal a great sensitivity to the properties of motion events across the different scenarios presented. This finding supports Croft, Barðdal, Hollmann, Sotirova and Taoka, (2010) and Hendriks and Hickmann (2015) who argue that in addition to classifying whole languages as S- or V-framed, one should also look at expression preferences related to individual motion events. It also supports the idea that linguistic typology might be better represented as a continuum, rather than a dichotomy (cf. Ibarretxe-Antuñano, 2009; Slobin, 2006). This further supports the view that language acquisition is not only guided by general cognitive developmental principles, but also by the language-specific features of the languages to be acquired.

\section{Implications and future research directions}

Future research pursuing these questions should expand the experimental design presented here in at least two ways. First, it should include more languages, particularly more V-languages to explore further intra-type variation in these languages. For example, results reported in the literature for Turkic languages (V-language) differ from those for French, showing that such languages present a more typically verb-framed pattern and less overall variation of expression than French (cf. Hickmann et al., 2009b for French; Allen et al., 2007, and Özçalişkan \& Slobin, 1999 for Turkish; Tusun, 2018 for Uyghur). Second, to further understand the influence of typology on motion expression, it is necessary to look at a variety of motion events, including not only voluntary motion, but also caused motion and placement events. The present study shows that speakers of the same language do not behave in similar ways across different event types, a result which may further enrich our understanding of motion description and further inform motion event typologies.

\section{Conclusion}

The aim of this study was to determine the extent to which the acquisition of voluntary motion expression is determined by general cognitive and/or language-specific factors. The findings are in line with those of previous studies on the typological status of English and German as S-languages, and French as a V-language, but also call for a 
detailed study of more varied motion events and their individual expression in those and other languages (cf. also Croft et al., 2010; Hendriks \& Hickmann, 2015). French in particular seems to vary the patterns of motion description, a finding that is mostly related to the types of events described. Elaborating studies on motion expression by including a variety of motion events should allow a better understanding of the underlying reasons for speakers' choices of Path and/or Manner focus.

From a developmental point of view, the data show general progressions in the acquisition of motion expression in all three languages, suggesting the influence of general (and perhaps universal) cognitive determinants. However, robust differences across and within typological language groups at all ages also indicate that language-specific features influence the development of spatial language. To better understand these two forces and timing of their impact, future research must examine production in more diverse languages and tasks.

Acknowledgements. The research reported in this paper is part of a French-German research project entitled 'LANGACROSS' and was financially supported by the French (ANR) and German (DFG) national funding agencies for research. The German data were collected by Anne-Katharina Harr as part of her doctoral thesis. We thank all the participating schools, pupils and students in the UK, France and Germany for their cooperation. The second author of this paper, Maya Hickmann, passed away during the writing up of the article. She will be much missed by friends and colleagues, not least by the first author. Finally, we thank two anonymous reviewers and the editor for their helpful comments.

\section{References}

Allen, S., Özyürek, A., Kita, S., Brown, A., Furman, R., \& Ishizuka, T. (2007). Language-specific and universal influences in children's syntactic packaging of Manner and Path: a comparison of English, Japanese, and Turkish. Cognition 102, 1, 16-48.

Aske, J. (1989). Path predicates in English and Spanish: A closer look. In K. Hall, M. Meacham \& R. Shapiro (eds.), Proceedings of the 15th annual meeting of the Berkeley Linguistics Society, 1-14.

Berman, R. A., \& Slobin, D. I. (eds.) (1994). Different ways of relating events in narrative: a crosslinguistic developmental study. Hillsdale, NJ: Lawrence Erlbaum.

Bowerman, M. (1996). The origins of children's spatial semantic categories: Cognitive vs. linguistic determinants. In J. J. Gumperz \& S. C. Levinson (eds.), Rethinking linguistic relativity (pp. 145-76). Cambridge: Cambridge University Press.

Bowerman, M., \& Choi, S. (2001). Shaping meanings for language: universal and language-specific in the acquisition of spatial semantic categories. In M. Bowerman \& S. C. Levinson (eds.), Language acquisition and conceptual development (pp. 475-511). Cambridge: Cambridge University Press.

Bunger, A., Trueswell, J., \& Papafragou, A. (2012). The relation between event apprehension and utterance formulation in children: evidence from linguistic omissions. Cognition 122, 135-149.

Choi, S. (2011). Language-specificity of motion event expressions in young Korean children. Language, Interaction and Acquisition (LIA) 2, 1, 157-84.

Choi, S., \& Bowerman, M. (1991). Learning to express motion events in English and Korean: The influence of language-specific lexicalization patterns. Cognition, 41, 83-121.

Cowan, N. (2014). Short-term and working memory in childhood. In P.J. Bauer and R. Fivush (eds.), The Wiley handbook on the development of children's memory (pp. 202-229). John Wiley Publishers.

Croft, W., Barðdal, J., Hollmann, W., Sotirova, V., \& Taoka, C. (2010). Revising Talmy's typological classification of complex event constructions. In Boas, H.C. (ed.), Contrastive studies in construction grammar (pp. 201-235). Amsterdam: John Benjamins.

Delage, A., \& Frauenfelder, U. (2019). Syntax and Working Memory in typically-developing children. Language, Interaction and Acquisition, 10,2, 141-176.

Filipović, L. (2007). Language as a witness: Insights from cognitive linguistics. International Journal of Speech, Language and the Law, 14,2, 245-267. 
Gathercole, S. E. (1999). Cognitive approaches to the development of short-term memory. Trends in Cognitive Sciences, 3(11), 410-419. doi:10.1016/S1364-6613(99)01388-1

Harr, A.-K. (2012). The impact of language-specific factors in first language acquisition: The expression of motion in French and German. Series: Studies on Language Acquisition. Berlin: Mouton de Gruyter.

Hendriks, H., \& Hickmann, M. (2015). Finding one's Path into another language: On the expression of boundary crossing by English learners of French. Modern Language Journal, 99, Supplement, 14-31.

Hickmann, M. (2003). Children's discourse: person, space and time across languages. Cambridge: Cambridge University Press.

Hickmann, M., Hendriks, H., \& Champaud, C. (2009a). Typological constraints on motion in French and English child language. In J. Guo, E. Lieven, S. Ervin-Tripp, N. Budwig, K. Nakamura \& Ş. Özçalışkan (Eds.), Crosslinguistic approaches to the psychology of language: Research in the tradition of Dan Isaac Slobin (pp. 209-24). New York: Psychology Press.

Hickmann, M., Taranne, P., \& Bonnet, P. (2009b). Motion in first language acquisition: Manner and Path in French and English child language. Journal of Child Language, 36, 705-41.

Hickmann, M., \& Hendriks, H. (2010). Typological constraints on the acquisition of spatial language in French and English. In H. Hendriks, M. Hickmann \& K. Lindner (eds.), Space, language, and cognition: developmental perspectives. Special issue of Cognitive Linguistics, 21, 189-215. doi:10.1515/ COGL.2010.007.

Hickmann, M., Hendriks, H., Harr, A.K., \& Bonnet, P. (2018). Caused motion across child languages: A comparison of English, German and French. Journal of Child Language, 45(6), 1247-1274.

Ibarretxe-Antuñano, I. (2009). Path salience in motion events. In J. Guo, E. Lieven, N. Budwig, Ervin-Tripp, K. Nakamura \& Ş. Özčalışkan (eds.), Crosslinguistic approaches to the psychology of language: Research in the tradition of Dan Isaac Slobin (pp. 403-414). New York: Psychology Press.

Ji, Y., Hendriks, H., \& Hickmann, M. (2011). Children's expression of voluntary motion events in English and Chinese. Journal of Foreign Languages, 34(4), 2-20.

Levelt, W. J. M. (1981). The speaker's linearization problem. Philosophical Transactions of the Royal Society, 295, 305-315.

Maguire, M., Hirsch-Pasek, K., Golinkoff, R., Imai, M., Haryu, E., Vanegas, S., Okada, H., Pulverman, R., \& Sanchez-Davis, B. (2010). A developmental shift from similar to language-specific strategies in verb acquisition: a comparison of English, Spanish, and Japanese. Cognition, 114, 299-319.

Naigles, L. R., Eisenberg, A. R., Kako, E. T., Highter, M., \& McGraw, N. (1998). Speaking of motion: Verb use in English and Spanish. Language and Cognitive Processes, 13, 521-49.

Newcombe, N. S., Uttal, D.H., \& Sauter, M. (2013). Spatial development. In P. Zelazo (ed.), Oxford handbook of developmental psychology, Vol. 1: Body and mind (pp. 564-590). New York: Oxford University Press

Nys, M., Gyselinck, V., \& Hickmann, M. (2016). The role of visuo-spatial abilities and working memory in the development of children's spatial representation of a virtual route. European Workshop on Imagery and Cognition (EWIC), Paris-Descartes, 6-8 June. http://ewic2016.parisdescartes.fr/

Özçalişkan, S. (2015). Ways of crossing a spatial boundary in typologically distinct languages. Applied Psycholinguistics, 36, 485-508.

Özçalişkan, S., \& Slobin, D. I. (1999). Learning how to search for the frog: Expression of Manner of motion in English, Spanish and Turkish. In A. Greenhill et al. (eds.), BUCLD 23 Proceedings (pp. 541-552). Sommerville, MA: Cascadilla Press.

Özçalişkan, S., \& Slobin, D. I. (2003). Codability effects on the expression of Manner of motion in Turkish and English. In A. Sumru-Özsoy, D. Akar, M. Nakipoglu-Demiralp, E. Erguvanli-Taylan \& A. Aksu-Koç (Eds.), Studies in Turkish linguistics, (pp. 259-270). Istanbul: Boğažici University Press.

Papafragou, A., Massey, C., \& Gleitman, L. (2002). Shake, rattle, 'n' roll: the representation of motion in language and cognition. Cognition, 84,2, 189-219.

Pinheiro, J., Bates, D., Debroy, S., Sarkar, D., \& R Core Team (2018). Nmle: Linear and Nonlinear Mixed Effects Models. R package version 3.1-131.1, URL:https://CRAN.R-project.org/package=nmle.

Pruden, S., Hirsch-Pasek, K., \& Golinkoff, R. (2008). Current events: how infants parse the world and events for language. In T. Shipley \& J. Zacks (eds.), Understanding events: from perception to action (pp. 160-192). Oxford: Oxford University Press.

Pulverman, R., Song, L., Pruden, S., Golinkoff, R., \& Hirsch-Pasek, K. (2013). Preverbal infants' attention to Manner and Path: Foundations for learning relational terms. Child Development, 84, 1, 241-252. 
R Core Team (2017). R: a language and environment for statistical computing. R Foundation for Statistical Computing, Vienna, Austria. URL: https://www.R-project.org/.

Slobin, D. I. (1996). From "Thought and Language" to "Thinking for Speaking". In J. J. Gumperz \& S. C. Levinson (eds.), Rethinking linguistic relativity (pp. 70-96). Cambridge: Cambridge University Press.

Slobin, D. I. (2003). Language and thought online: cognitive consequences of linguistic relativity. In D. Gentner \& S. Goldin-Meadow (eds.), Language in mind: Advances in the study of language and thought (pp. 157-192). Cambridge, MA: MIT Press.

Slobin, D. I. (2004). The many ways to search for a frog: linguistic typology and the expression of motion events. In S. Strömqvist \& L. Verhoeven (eds.), Relating events in narrative, vol.2: Typological and contextual perspectives (pp. 219-57). Mahwah: Erlbaum.

Slobin, D. I. (2006). What makes manner of motion salient? Explorations in linguistic typology, discourse, and cognition. In M. Hickmann \& S. Robert (eds.), Space in languages: Linguistic systems and cognitive categories (pp. 59-81). Amsterdam \& Philadelphia: John Benjamins.

Slobin, D. I., Bowerman, M., Brown, P., Eisenbeiss, S., \& Narasimhan, B. (2011). Putting things in places: Developmental consequences of linguistic typology. In J. Bohnemeyer \& E. Pederson (eds.), Event representation in language and cognition (pp. 134-65). New York: Cambridge University Press.

Slobin, D. I., \& Hoiting, N. (1994). Reference to movement in spoken and signed languages: Typological considerations. Paper presented at the 20th Annual Meeting of the Berkeley Linguistics Society, University of California, Berkeley.

Talmy, L. (1985). Lexicalization patterns: Semantics structure in lexical forms. In T. Shopen (ed.), Language typology and syntactic description (vol.3): Grammatical categories and the lexicon (pp. 36-149). Cambridge: Cambridge University Press.

Talmy, L. (2000). Towards a cognitive semantics. Harvard: MIT Press.

Talmy, L. (2012). Main verb properties. International Journal of Cognitive Linguistics, 3,1, 1-24.

Tusun, A. (2018). The acquisition of motion event expressions by Uyghur-Chinese early successive bilinguals. Unpublished Doctoral Dissertation, University of Cambridge.

\section{Appendix 1}

Description of stimuli used in the experiment

UP/DOWN items

(1) A squirrel arrives on the scene, runs up to a tree, runs up a tree, into and out of a hole, runs down and away.

(2) A caterpillar arrives on the scene and crawls towards a plant, then crawls up the plant to eat a leaf, crawls down and away.

(3) A bear arrives on the scene and walks towards a tree on his hind legs, climbs up the tree to get some honey, climbs down, and walks away.

(4) A cat arrives on the scene, runs up to a telegraph pole, then runs up the telephone pole to a birds' nest, drops an egg, jumps down and runs away.

(5) A mouse arrvies on the scene, tiptoes towards a table, climbs up the table along the table leg to take a piece of cheese, slides down, and tiptoes away.

(6) A monkey arrives on the scene and walks to a banana tree on its hind legs, climbs up the tree to take a banana, then slides down and walks away.

\section{ACROSS items}

(7) A man arrives on the scene running, runs across a country road and runs away.

(8) A girl arrives on the scene cycling, rides across railroad tracks, then cycles away.

(9) A baby crawls on a sidewalk, crawls across a street and crawls away.

(10) A boy runs towards a river, swims across the river and runs away.

(11) A boy runs in the snow towards a frozen river, slides across and walks away.

(12) A girl walks onto a frozen lake from a jetty, skates across the lake and comes off the lake to walk away. 


\section{Appendix 2}

Examples of three stimuli

\section{UP/DOWN}

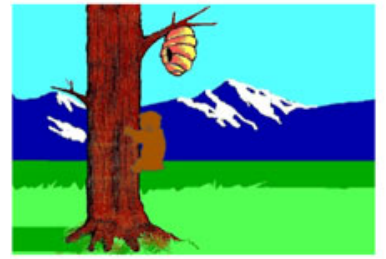

Bear climbing up tree

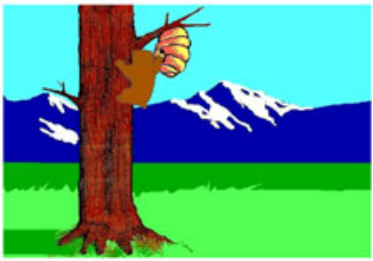

Bear getting honey

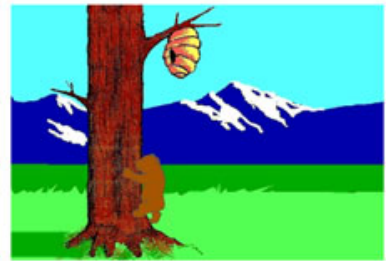

Bear climbing down from tree

\section{ACROSS}

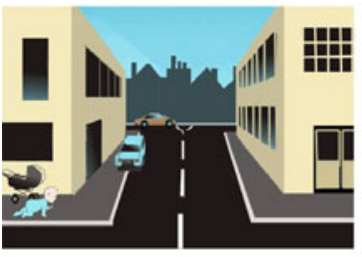

Baby crawling on sidewalk

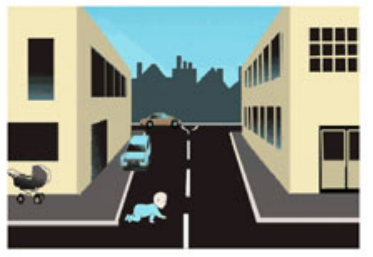

Baby crossing street

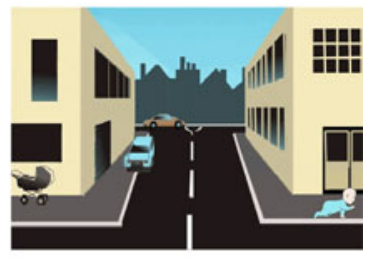

Baby arriving at other side

\section{CONTROL}
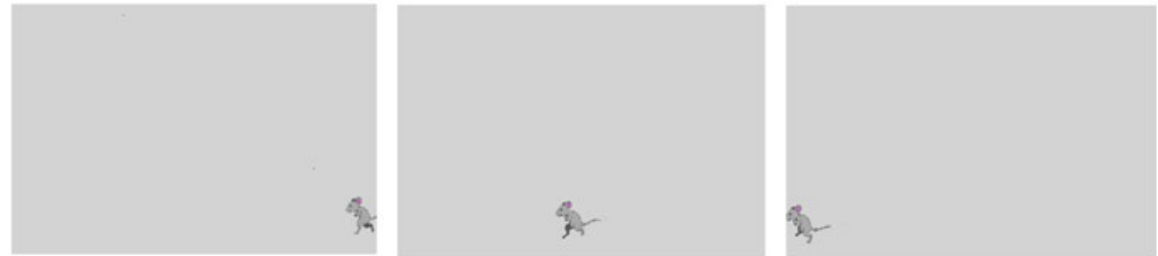

Mouse tiptoeing across empty screen from right to left 


\section{Appendix 3}

\begin{tabular}{ll}
\hline Contrasts for Language & \\
\hline Contrast 1: & French vs Other (English and German) \\
\hline Contrast 2: & English vs German \\
\hline Contrasts for Age & 3 vs 4 \\
\hline Contrast 1: & 4 vs 5 \\
\hline Contrast 2: & 5 vs 6 \\
\hline Contrast 3: & 6 vs 8 \\
\hline Contrast 4: & 8 vs 10 \\
\hline Contrast 5: & 10 vs Adults \\
\hline Contrast 6: & \\
\hline Contrasts for Item type & Control vs Test Items (acRoss, UP and Down) \\
\hline Contrast 1: & ACRoss vs Vertical Items (UP and Down) \\
\hline Contrast 2: & UP vs Down Items \\
\hline Contrast 3: & \\
\hline
\end{tabular}

Cite this article: Hendriks H, Hickmann M, Pastorino-Campos C (2022). Running or crossing? Children's expression of voluntary motion in English, German, and French. Journal of Child Language 49, 578-601. https://doi.org/10.1017/S0305000921000271 